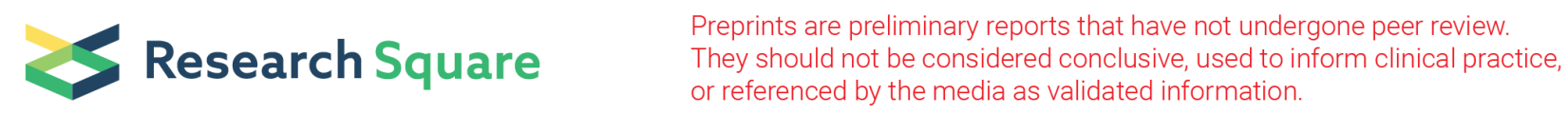

\title{
Prevalence of Arbovirus Antibodies in Young Healthy Adult Population in Brazil
}

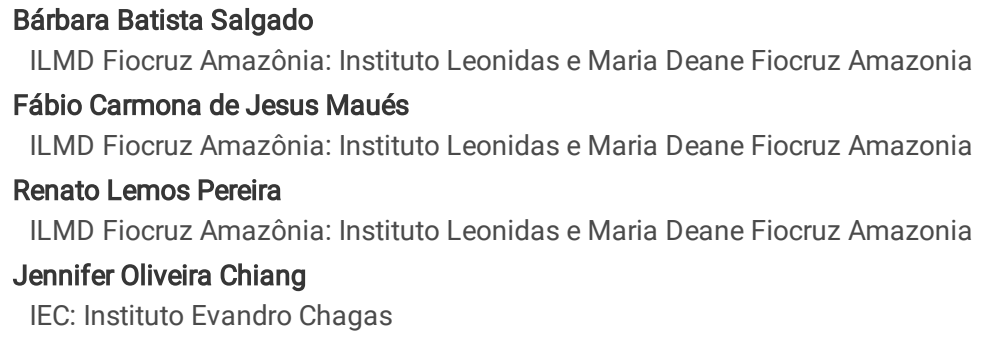

\section{Research Article}

Keywords: Arbovirus, seroprevalence, hemagglutination inhibition assay, public health, military personnel, cross-reactivity.

Posted Date: May 4th, 2021

DOl: https://doi.org/10.21203/rs.3.rs-434751/v1

License: @ (i) This work is licensed under a Creative Commons Attribution 4.0 International License. Read Full License

Version of Record: A version of this preprint was published at Parasites \& Vectors on August 14th, 2021. See the published version at https://doi.org/10.1186/s13071-021-04901-4. 


\section{Abstract}

The emergence and re-emergence of infectious diseases are a cause for worldwide concern. The introduction of Zika and Chikungunya disease in the Americas has exposed unforeseen medical and logistical challenges for public health systems. Moreover, the lack of preventive measures and vaccination against known and emerging mosquito-transmitted pathogens, and the occurrence of unanticipated clinical complications, has produced an enormous social and economic impact in the affected populations. In this study, we aimed to measure the seroprevalence of endemic and emerging viral pathogens in military personnel stationed in Manaus, Amazonas state. We measured the seroprevalence of antibodies against nineteen endemic and emerging viruses in a healthy military personnel cohort using a Hemagglutination Inhibition Assay (HIA). Overall, DENV seroprevalence was $60.4 \%$, and $30.9 \%$ of the individuals reacted against ZIKV. Also, 46.6\%, 54.7\%, 51.3\% and 48.7\% individuals reacted against West Nile virus (WNV), Saint Louis Encephalitis virus (SLEV), Ilheus virus (ILHV) and Rocio virus (ROCV), respectively. Individuals with high DENV HIA titre reacted more frequently with ZIKV or WNV compared to those with low HIA titres. Observed cross-reactivity between Flaviviruses varied depending on the virus serogroup. Additionally, $0.6 \%$ and $0.3 \%$ individuals were seropositive for Oropouche virus (OROV) and Catu virus (CATUV) from the family Peribunyaviridae, respectively. All samples were negative for Eastern Equine Encephalitis virus (EEEV), Western Equine Encephalomyelitis virus (WEEV), Mayaro virus (MAYV), Mucambo virus (MUCV) and CHIKV from the family Togaviridae. In conclusion, a high proportion of individuals in our high-risk population ( $60 \%)$ lacked antibodies against major endemic and emerging viruses, which makes them susceptible for further infections. Military personnel serving in the Amazon region could serve as sentinels to strengthen global infectious disease surveillance, particularly in remote areas.

\section{Introduction}

Deforestation, urbanization and climate change have led to perpetual public health challenges of infectious diseases worldwide [1]. In the last few decades, viruses transmitted by arthropods have caused numerous outbreaks worldwide in humans and animals, causing diseases ranging from sub-clinical or mild, through febrile, encephalitic, haemorrhagic, or arthritogenic disease, with a significant proportion of fatalities [2, 3].

Dengue virus (DENV), one of the foremost studied arboviruses, is still responsible for millions of infections and numerous deaths worldwide [4]. Consecutive dengue epidemics have been occurring in Brazil since 1986, and more than four million cases of dengue fever (DF) had already been recorded to date [5, 6]. Moreover, all four dengue virus serotypes that cause human disease have been detected in Brazil, and at least two serotypes co-circulate in rural and urban communities $[7,8,9]$. In the absence of effective therapeutics to treat dengue disease, there has also been an increase in dengue-associated deaths along with increasing disease incidence $[5,9]$.

The social and economic impact attributed to the recent Zika virus (ZIKV) and Chikungunya virus (CHIKV) disease introductions, driven by the large sheer number of human infections and associated pathology in Brazil and the Americas are well documented [10, 11]. In addition, the recent isolation of West Nile virus (WNV) from equine hosts represents an additional emerging virus circulating in Brazil [12]. It is worth pointing out that in Brazil the co-circulation of several flaviviruses (like Dengue, Zika, Yellow Fever, Saint Louis encephalitis, llheus and others), complicates the serological diagnosis of these emerging infections, due to the extensive flavivirus cross-reactivity in the serological assays $[13,14,15,16]$. Whilst many current arboviruses do not appear to cause pathology in humans or animals, this large number of widely different and highly adaptable arboviruses provides an immense resource for the emergence of new pathogens in the future $[2,11]$. Epidemiological and molecular clock studies demonstrate that ZIKV and CHIKV introduction in Brazil happened up to a year before their detection, moreover these studies also point towards clinical misdiagnosis in some cases $[17,18]$. Combating these pathogens has historically been driven by the circumstances: expecting the unexpected and being prepared to respond when the unexpected occurs. Therefore, understanding the epidemiology of these emerging and endemic pathogens is necessary to ascertain their public health impact and to respond efficiently to these epidemiologic and diagnostic challenges.

Furthermore, compared to civilian population, military personnel live in a communal nature, train in diverse locations like the Amazon rainforest and participate in humanitarian aid in adverse conditions, alongside suboptimal hygiene and stress in the field, which increases their risk of contracting emerging infectious diseases. Theoretically they can act as an epidemiological bridge - a sentinel population- between an emerging pathogen and their susceptible civil hosts. However, we have little data about the serological status before or during recent arbovirus outbreaks and the role of cross-reactive antibodies against these emerging viruses. Hence, in this study we evaluated the prevalence and antibody reactivity among military personnel using a cell-based assay against major endemic and emerging arboviruses from three different virus families.

\section{Materials And Methods}

Ethics

This study was approved by the Universidade Federal do Amazonas (UFAM) and Universidade Nilton Lins (UNINILTONLINS) research ethics committee, in accordance with Brazilian law, which complied with the Helsinki declaration. All the study participants signed an informed consent prior to enrolment.

Study population and sample collection

The study population comprised of Brazilian army personnel stationed in barracks scattered throughout Brazil and participating in a Jungle training course at the Centro de Instrução de Guerra na Selva (CIGS), located in Manaus, Amazonas State. Upon consent, consecutive individuals were enrolled in this observational and cross-sectional study until attaining calculated sample size between January 2014 and December 2015 . A total of $4 \mathrm{~mL}$ of blood was drawn from each participant (using EDTA tubes, BD Vacutainer), subsequently tubes were centrifuged and serum was separated and stored at $-80^{\circ} \mathrm{C}$ until further analysis. 
Seroprevalence has been shown to vary greatly depending on the study population, age, sex and the serological assay employed for antibody testing. Additionally, objective of this study was to estimate the seroprevalence of nineteen arboviruses from three different virus families, which range between $<1 \%$ to $>50 \%$ depending on the geographical location of the study participants $[9,19,20,21,22]$. Since our study population is composed of military personnel that had resided in diverse locations throughout Brazil, an intermediate prevalence of $25 \%$ was chosen to accommodate this variability. A sample size of 285 individuals was calculated using an estimated prevalence of $25 \%$ and $95 \%$ confidence interval for a large population with a desired precision of 0.05 . To avoid a reduction in statistical power in case of missing data, we recruited 300 individuals (assuming a maximum of $5 \%$ of participants excluded from analyses because of missing data). However, two questionnaires were incomplete and removed from the analysis.

After serological analysis, post-hoc analysis was performed to determine if sample size used in this study was appropriate. DENV-2 seroprevalence of $58.4 \%$ was among the highest of all the pathogens tested in this study and using a sample size of 298 had a $90 \%$ confidence interval and precision of 0.05 . Also, post-hoc analysis with lowest seroprevalence of $0.3 \%$ for CATUV observed in this study, a sample size of 298 had a $99.99 \%$ confidence interval and precision of 0.05 Sample size calculation and power analysis was performed using the GPower 3.1 and Epi Info software.

Hemagglutination inhibition test

The serological tests were performed at the Instituto Evandro Chagas (IEC), (Belém, Pará). All the 298 serum samples collected were subjected to a hemagglutination inhibition assay (HIA) with a titration cut-off of 1:20 serum dilution, as previously described [20, 23, 24]. Samples were tested by HAI test to detect antibodies reactive to the following viral families: Flaviviridae (Flavivirus genus): Yellow Fever virus (YFV), Dengue Virus (DENV) serotypes 1 to 4 (DENV1, DENV-2, DENV-3 and DENV-4), Zika virus (ZIKV), Saint Louis Encephalitis virus (SLEV), West Nile virus (WNV), Ilheus virus (ILHV), Rocio virus (ROCV); Togaviridae (Alphavirus genus): Eastern Equine Encephalitis virus (EEEV), Western Equine Encephalomyelitis virus (WEEV), Mayaro virus (MAYV), Mucambo virus (MUCV), Chikungunya virus (CHIKV); Peribunyaviridae (Orthobunyavirus genus): Oropouche virus (OROV), Tacaiuma virus (TCMV) and Catu virus (CATUV).

Spatial analysis and virus distribution

PubMed, Science Direct, LICACS, Web of Science and Medline databases were searched by keywords (Fig. 5) to identify research papers with dengue virus seroprevalence data. QGIS Software version 2.18.26 for macOS was used to plot spatial distribution of dengue prevalence in Brazilian cities, Supplementary Table 1 lists studies included in this analysis between 1980 and June 2020. Hot spot detection maps were plotted using publicly available data for Dengue, Zika and Chikungunya virus incidences between 2014-2018 (Ministry of Health Brazil, https://www.saude.gov.br/boletins-epidemiologicos).

\section{Data analysis}

To analyze the clustering of study subjects according to their HIA serum titers against all viral species analyzed, we normalized their serological dilution values using the $\log _{2}$ of the inverse titer value, calculated with the formula normalized_titer $=\log _{2}[1 /$ titer] [25]. We then constructed a heatmap plot of serum HIA normalized titer levels with the Manhattan clustering method using the heatmap package version 1.0.12 (https://cran.r-project.org/package=pheatmap) in $\mathrm{R}$ for macOS with RStudio (R version 3.6.2, RStudio version 1.2.5033). The bubble plots depicting the percentages of seropositive individuals was done using Microsoft Excel 2019.

\section{Results}

In the current study, we performed a cross-sectional serological analysis that evaluated the seroprevalence of antibodies against endemic and emerging viruses. We aimed to assess the pre-Zika and chikungunya epidemic serological status of individuals in a highly mobile cohort, to better understand and estimate the size of the virus-exposed and susceptible populations. We recruited 300 individuals, and 298 were included in the analyses (Fig. 1). Serological results are summarized in Table 1. All study participants were male, with a mean age of 27.98 years and median age of twenty-six years (IQR, 24-31 years). Study participants had served in the military since attaining eighteen years of age and had resided in several Brazilian states, hence, we could not ascertain the local of infection for the pathogens tested in this study. We tested the serum of each of the study participant $(n=298)$ for nineteen different viruses from three virus families (eleven viruses from Flaviviridae, three viruses from Peribunyaviridae and five viruses from Togaviridae) by Hemagglutination Inhibition Assay (HIA). Among the three virus families tested, the majority of the individuals $(251 / 298,82.2 \%)$ reacted against the viruses from the Flaviviridae family (genus Flavivirus) (Table 1 and Figs. 1 and 2). The seroprevalence for the Peribunyaviridae, family was 0.6\% and 0.3\% (2/298, OROV and 1/298 CATUV, respectively). Our entire study population was negative for all five viruses tested from the Togaviridae family (Table 1). 
Table 1

Prevalence of antibodies against principal human arboviruses

\begin{tabular}{|c|c|c|c|c|c|}
\hline Classification & Virus* & $\begin{array}{l}\text { Total } \\
\% \#\end{array}$ & $\begin{array}{l}\text { Age 18-25 years } \\
\% \#\end{array}$ & $\begin{array}{l}\text { Age } 26-35 \text { years } \\
\% \#\end{array}$ & $\begin{array}{l}\text { Age }>35 \text { years } \\
\% \#\end{array}$ \\
\hline \multicolumn{6}{|l|}{ Flaviviridae } \\
\hline \multirow[t]{2}{*}{ Yellow Fever Virus Group } & YFV/17D & $82.9 \%(247 / 298)$ & $82.5 \%(113 / 137)$ & $81.5 \%(97 / 119)$ & $87.8 \%(36 / 41)$ \\
\hline & YFV & $45.6 \%(136 / 298)$ & $42.3 \%(58 / 137)$ & $50.4 \%(60 / 119)$ & $41.5 \%(17 / 41)$ \\
\hline \multirow[t]{4}{*}{ Dengue Virus Group } & DENV-1 & $56.7 \%(169 / 298)$ & $51.8 \%(71 / 137)$ & $62.2 \%(74 / 119)$ & $56.1 \%(23 / 41)$ \\
\hline & DENV-2 & $58.4 \%(174 / 298)$ & $53.3 \%(73 / 137)$ & $63.9 \%(76 / 119)$ & $58.5 \%(24 / 41)$ \\
\hline & DENV-3 & $56.4 \%(168 / 298)$ & $50.4 \%(69 / 137)$ & $61.3 \%(73 / 119)$ & $61.0 \%(25 / 41)$ \\
\hline & DENV-4 & $48.3 \%(144 / 298)$ & $43.1 \%(59 / 137)$ & $52.1 \%(62 / 119)$ & $53.7 \%(22 / 41)$ \\
\hline Spondweni Group & ZIKV & $30.9 \%(92 / 298)$ & $27.7 \%(38 / 137)$ & $31.9 \%(38 / 119)$ & $36.6 \%(15 / 41)$ \\
\hline \multirow[t]{2}{*}{ Japanese Encephalitis Virus Group } & WNV & $46.6 \%(139 / 298)$ & $40.9 \%(56 / 137)$ & $53.8 \%(64 / 119)$ & $43.9 \%(18 / 41)$ \\
\hline & SLEV & $54.7 \%(163 / 298)$ & $48.9 \%(67 / 137)$ & $63.0 \%(75 / 119)$ & $48.8 \%(20 / 41)$ \\
\hline \multirow[t]{2}{*}{ Ntaya Virus Group } & ILHV & $51.3 \%(153 / 298)$ & $48.1 \%(66 / 137)$ & $54.6 \%(65 / 119)$ & $51.2 \%(21 / 41)$ \\
\hline & ROCV & $48.7 \%(145 / 298)$ & $43.8 \%(60 / 137)$ & $52.9 \%(63 / 119)$ & $51.2 \%(21 / 41)$ \\
\hline \multicolumn{6}{|l|}{ Peribunyaviridae } \\
\hline Simbu serogroup & OROV & $0.7 \%(2 / 298)$ & $0.7 \%(1 / 137)$ & $0.8 \%(1 / 119)$ & $0 \%(0 / 41)$ \\
\hline Guama serogroup & CATUV & $0.3 \%(1 / 298)$ & $0 \%(0 / 137)$ & $0 \%(0 / 119)$ & $2.4 \%(1 / 41)$ \\
\hline Anopheles A serogroup & TCMV & $0 \%(0 / 298)$ & $0 \%(0 / 137)$ & $0 \%(0 / 119)$ & $0 \%(0 / 41)$ \\
\hline \multicolumn{6}{|l|}{ Togaviridae } \\
\hline \multirow[t]{2}{*}{ Semliki Forest virus complex } & MAYV & $0 \%(0 / 298)$ & $0 \%(0 / 137)$ & $0 \%(0 / 119)$ & $0 \%(0 / 41)$ \\
\hline & CHIKV & $0 \%(0 / 298)$ & $0 \%(0 / 137)$ & $0 \%(0 / 119)$ & $0 \%(0 / 41)$ \\
\hline Eastern Equine Encephalitis Complex & EEEV & $0 \%(0 / 298)$ & $0 \%(0 / 137)$ & $0 \%(0 / 119)$ & $0 \%(0 / 41)$ \\
\hline Western Equine Encephalitis Complex & WEEV & $0 \%(0 / 298)$ & $0 \%(0 / 137)$ & $0 \%(0 / 119)$ & $0 \%(0 / 41)$ \\
\hline Venezuelan Equine Encephalitis Complex & MUCV & $0 \%(0 / 298)$ & $0 \%(0 / 137)$ & $0 \%(0 / 119)$ & $0 \%(0 / 41)$ \\
\hline Negatives & & $15.8 \%(47 / 298)$ & $16.1 \%(22 / 137)$ & $16.8 \%(20 / 119)$ & $12.2 \%(5 / 41)$ \\
\hline
\end{tabular}

\# HI titre $\geq 1: 20$

* Flaviviridae (Flavivirus genus): Dengue Virus (DENV) serotypes 1 to 4 (DENV-1, DENV-2, DENV-3 and DENV-4), Zika virus (ZIKV), Saint Louis Encephalitis virus (SLEV), West Nile virus (WNV), Ilheus virus (ILHV) and Rocio virus (ROCV); Peribunyaviridae (Orthobunyavirus genus): Oropouche virus (OROV), Catu virus (CATUV) and Tacaiuma virus (TCMV); Togaviridae (Alphavirus genus): Mayaro virus (MAYV), Chikungunya virus (CHIKV), Eastern Equine Encephalitis virus (EEEV), Western Equine Encephalomyelitis virus (WEEV) and Mucambo virus (MUCV).

Antibodies to DENV were predominant among soldiers and varied between $48.3 \%$ and $58.4 \%$, depending on the serotype of the virus (Table 1 and Fig. 3 ). We observed, that during the ongoing 2014 ZIKV epidemic, $30.9 \%$ participants had anti-ZIKV antibodies (Table 1 ). Also $46.6 \%$ and $54.7 \%$ study participants were reactive for WNV and SLEV of the Japanese Encephalitis serogroup, respectively. ILHV and ROCV, from the Ntaya virus serogroup, had a seroreactivity of $51.3 \%$ and $48.7 \%$, respectively. Furthermore, we observed an apparent relationship between increasing age and percentage HIA positivity, however, no statistically significant differences were observed between seroprevalence data when stratified by age (Table 1, data not shown).

We then evaluated the clustering of individuals according to their serological titres against all viruses tested. We observed that our population clustered into three groups: $A(n=70), B(n=59)$, and C ( $n=169)$ (Fig. 2). Group A was a distinct group where most individuals had HIA titres against all flavivirus tested. Individuals in groups A and B showed a similar clustering pattern, with high HIA titers to DENV1-3 and YFV-17D (vaccine strain), but differed in their positivity to ZIKV (98.6\% vs $35.6 \%$, respectively), showing lower HIA titres than subjects in group A overall. Group C represented a group with $29.6 \%$ seropositivity to YF17D vaccine strain (compared to $98.6 \%$ and $100 \%$ in groups $A$ and $B$, respectively), and a decreased fraction of flavivirus-seroreactive individuals overall (YFV 10\%, vs 98.6 and 84.7 in groups A and B, respectively); only two individuals were seroreactive to ZIKV (1.2\%). Peribunyaviridae-positive individuals clustered with groups $A(n=1)$ and $B(n=2)$.

Next, we plotted a bubble chart to understand the distribution of anti-DENV antibodies per serotype (Fig. 3). A higher proportion of individuals were reactive against DENV-1 and DENV-2, $\geq 320$ HIA titre. In addition, to assess the cross-reactivity between tested Flaviviruses, we analysed the reactivity of DENV-1- or DENV-2-positive individuals with their corresponding reactivity for DENV-2 or DENV-1, WNV or ZIKV (Fig. 4). We observed that individuals with higher HIA titre 
for DENV-1 or DENV-2 reacted with WNV or ZIKV more frequently, in contrast, individuals with lower DENV titres demonstrated low or no reactivity against WNV and ZIKV. Additionally, DENV-1 or DENV-2 positive individuals reacted more frequently with WNV compared to ZIKV (Fig. 4).

Furthermore, 5\% (15/295) and 17.2\% (51/296) individuals self-reported previous malaria and dengue virus infection, respectively. We performed a chi-square test to assess if self-reported dengue infection rates were similar to results observed by serological diagnosis performed in this study. We observed that serological testing showed a higher percentage of positive individuals than self-reported disease $(\mathrm{p}<0.0001$, data not shown).

To understand overall seroprevalence and distribution of DENV in Brazil, studies between 1980 and 2020 were identified from scientific databases and spatial analysis was performed (Figs. 5 and 6 and supplementary Table 1). Most of these studies used different sampling strategy, age groups and dengue detection assay that impede comparison between them (Supplementary Table 1). However, several large cities demonstrated an increase in DENV prevalence since first detection. Most Brazilian cities have more than one dengue serotype circulating, for examples Manaus in Amazonas state all four DENV serotypes have been detected. Hence, this prevalence data may be important for future DENV vaccination and arbovirus disease control strategies.

In summary, we observed that a major part of our tested population had antibodies to DENV, however, the absence or low reactivity against several arboviruses makes this population susceptible for endemic and emerging arboviral diseases.

\section{Discussion}

Emerging and re-emerging arbovirus infections pose a serious public health threat in tropical and subtropical regions worldwide [2, 3]. In this study, we observed that half of the study population was seropositive for dengue virus, however, a major proportion of our study population was susceptible to endemic and emerging viruses. The presence of a large and susceptible population, and the abundant presence of mosquito vector populations are important factors that contributed to the recent large outbreaks of ZIKV and CHIKV reported in Brazil and other Latin American countries, upon the introduction of the viral diseases in the continent. Also, a lack of adequate molecular diagnostic tools, and the antibody cross-reactivity between these endemic viruses, contributed to their spread and delayed diagnosis.

All four dengue serotypes are endemic in Brazil, and at least two of the four serotypes circulate in most of the Brazilian states [7, 9, 26, 27]. For example, in Manaus, Amazonas state, all four DENV serotypes have been detected [28]. Likewise, seroprevalence have been shown to be in the range of 15 to $80 \%$, depending on the population and region; in addition, the prevalence of DENV infection has been shown to increase with age [5, 7, 9, 19, 29]. We observed a maximum seroprevalence of $58.4 \%$ for DENV-2 among our cohort. Also, HIA titres for DENV-1 and 2 antibodies were higher compared to DENV-3 and 4 , which may be partially explained by the late introduction of these viruses in Brazil [7, 26]. However, we did not observe any correlation between age and seroprevalence frequencies as observed in other studies. Military personnel are dynamic populations, and they move constantly from one region to another for duty; this factor could explain the discrepancy observed between the lack of correlation between age and seroprevalence in our cohort as compared with the general population that resides in the same location over a period of time. Our data suggest that an important factor in the development of the overwhelming epidemic of ZIKV and CHIKV in Brazil could be attributed to the low level or absence of pre-existing antibody responses, combined with the ample presence of Aedes aegypti in the urban setting [11, 29, 30, 31].

More individuals had antibodies reactive against the Yellow fever vaccine strain 17D compared to the wildtype strain. Moreover, the decreasing reactivity toward wild type strain may be an indicator of gradual decrease of antibody titres overtime after vaccination. Recently, demonstrated a need for booster doses at 10 years after primary vaccination in travellers to endemic region, endemic population, and high-risk individuals like military personnel to heighten the 17DD-YF specific immune response and to achieve efficient immunity.

The presence of heterologous neutralizing antibody titres are inversely correlated with the severity of patients with a second DENV infection [8, 32, 33, 34]. Additionally, over $30 \%$ of the individuals had antibodies against major endemic and emerging Flaviviruses tested in this study. We cannot rule out multiple flavivirus infections in the same individual. These findings, along with other reports, indicate that SLEV, WNV, ILHV and ROCV circulation in Brazil is largely unknown, and there may be epidemiological implications of the co-circulation of these arboviruses [16, 19]. Overall, in vivo or cohort studies are needed to ascertain role of multiple Flavivirus infection in cross-protection or induction of a severe disease $[8,13,15,35]$. Regarding their role in disease and protection, low avidity antibodies against DENV have been shown to participate in severe disease, also poorly-neutralizing antibodies can participate in antibodydependent enhancement (ADE) in DENV infections [36, 37, 38]. Recent studies have demonstrated a role of DENV antibodies in causing ADE during ZIKV infection $[39,40]$. On the other hand, several studies have also demonstrated a lack of ADE like cytokine storm and partial protective role of these flavivirus cross-reactive antibodies upon ZIKV infection [41,42]. Nevertheless, comprehensive in vivo studies are necessary to ascertain role of these cross-reactive antibodies in ADE during ZIKV and other Flavivirus infections.

MAYV is endemic in the Amazon region and there have been imported cases in other regions of Brazil [21, 43]. A prevalence of more than 40\% for MAYV has been described in some Amazonian communities [21]. However, we did not observe any positive samples for the Alphavirus tested in our study. Similarly, we observed very low prevalence to OROV belonging to Peribunyaviridae. OROV is still localized in the Amazon region and is responsible for causing neurological disease in urban and rural areas [44]

One of the limitations of the present study is that it was not feasible to perform a neutralization assay to distinguish between dengue serotypes and confirm or rule out multiple infections or cross-reactivity. Although, most study participants were young male adults, these results are in accordance with previous studies on DENV prevalence $[9,29]$. Furthermore, given the size and geographical differences in Brazil, the estimates from one region or state cannot be used to understand epidemiology from the whole of Brazil. On the other hand, soldiers are a high-risk group because of the activities they are involved and their contact with endemic regions such as the Amazon rainforest. A very small proportion of the study population reported previous malaria infection, which suggests that most of the individuals lived in urban regions or have spent little time in the rural Amazon region, where $99.9 \%$ of the malaria cases are

Page 5/13 
described [45]. This might explain the low level or absence of antibodies against arboviruses described in the Amazonian region, such as OROPV and MAYV (Sakkas et al. 2018; Esposito \& Fonseca 2017). Moreover, only 17\% of the individuals tested in this study self-reported dengue infection, which was three times lower than that observed by serology. These unreported dengue infections could be asymptomatic subclinical infections or self-limiting fever without diagnosis or clinically not diagnosed as dengue. Our cluster analysis suggests that $~ 60 \%$ of our cohort comprehended a low Flavivirus-positive population and therefore susceptible to infection. Theoretically, susceptible military personnel could act as disease-spreading agents when returning to civil life when the combination of a susceptible population and specific vectors are present. More detailed serological surveys together with vector population assessment and viral detection strategies are needed to further characterize the extent of favourable factors that can contribute to future outbreaks, and to forecast potential public health needs.

Overall, mosquito control measures and integrated vector management are essential for control of all arboviruses, and were effective in controlling ZIKV and CHIKV outbreaks in Brazil and worldwide $[46,47,48]$. However, vector control precedes the decrease in herd immunity and the increase in the availability of susceptible populations [11,32]. Adaptions of these emerging viruses to urban vectors like Aedes aegypti or Culex quinquefasciatus and the decreasing herd immunity to them might facilitate further epidemics of endemic and emerging arboviruses [2,3]. Currently, differential clinical diagnosis is a major challenge when multiple viruses that cause similar clinical symptoms co-circulate $[13,14]$; moreover, the lack of adequate diagnostics tools can limit early identification and efforts to block outbreaks $[11,49]$. Warmer weather conditions brought on by the El Niño phenomenon and the destruction of the Amazon native forest can encourage a faster breeding and maturation cycles for Aedes and Anopheles mosquito populations [50]. Hence, an improved vector and febrile syndrome surveillance, along with basic understanding of arboviral-disease pathogenesis mechanisms are essential to prevent future outbreaks and can contribute to better control strategies.

\section{Declarations}

\section{Acknowledgement}

The authors would like to thank Commander Col. Alcimar for logistical support at the Centro de Instrução de Guerra na Selva (CIGS) and all military personnel for their participation.

\section{Ethics approval and consent to participate}

This study was approved by the Universidade Federal do Amazonas (UFAM) and Universidade Nilton Lins (UNINILTONLINS) research ethics committee, in accordance with Brazilian law, which complied with the Helsinki declaration. All the study participants signed an informed consent prior to enrolment.

\section{Consent for publication}

Patients signed informed consent regarding publishing their data.

\section{Competing interests}

The authors have no conflicting financial interests.

\section{Funding}

PL was supported by Fundação de Amparo à Pesquisa do Estado do Amazonas (FAPEAM) and ILMD/Fiocruz Amazônia-PROEP. FCJM received fellowship from the National Postdoctoral Program (PNPD/CAPES) and BBS is supported by scholarship from CAPES.

\section{References}

1. Fauci AS, Morens DM. The Perpetual Challenge of Infectious Diseases. New England Journal of Medicine. 2012;366 5:454-61; doi: 10.1056/NEJMra1108296. http://www.nejm.org/doi/abs/10.1056/NEJMra1108296.

2. Liang G, Gao X, Gould EA. Factors responsible for the emergence of arboviruses; strategies, challenges and limitations for their control. Emerging Microbes \& Infections. 2019;4 1:1-5; doi: 10.1038/emi.2015.18. https://www.tandfonline.com/doi/full/10.1038/emi.2015.18.

3. Weaver SC, Charlier C, Vasilakis N, Lecuit M. Zika, Chikungunya, and Other Emerging Vector-Borne Viral Diseases. Annual Review of Medicine. 2018;69 1:395-408; doi: 10.1146/annurev-med-050715-105122. http://www.annualreviews.org/doi/10.1146/annurev-med-050715-105122.

4. Guzman MG, Peeling RW, Kroeger A, Yoksan S, Gubler DJ, Simmons C, et al. Dengue: a continuing global threat. Nature Reviews Microbiology. 2010;8 12:S7-S16; doi: 10.1038/nrmicro2460. http://www.ncbi.nlm.nih.gov/pubmed/21079655.

5. Nunes PCG, Daumas RP, Sánchez-Arcila JC, Nogueira RMR, Horta MAP, dos Santos FB. 30 years of fatal dengue cases in Brazil: a review. BMC Public Health. 2019;19 1:13-1; doi: 10.1186/s12889-019-6641-4. https://bmcpublichealth.biomedcentral.com/articles/10.1186/s12889-019-6641-4.

6. Fares RCG, Souza KPR, Añez G, Rios M. Epidemiological Scenario of Dengue in Brazil. BioMed Research International. 2015;2015 5:1-13; doi: 10.1155/2015/321873. https://www.hindawi.com/journals/bmri/2015/321873/.

7. Salles TS, da Encarnação Sá-Guimarães T, de Alvarenga ESL, Guimarães-Ribeiro V, de Meneses MDF, de Castro-Salles PF, et al. History, epidemiology and diagnostics of dengue in the American and Brazilian contexts: a review. Parasites \& Vectors. 2018;11 1:19-2; doi: 10.1186/s13071-018-2830-8. https://parasitesandvectors.biomedcentral.com/articles/10.1186/s13071-018-2830-8.

8. Katzelnick LC, Fonville JM, Gromowski GD, Arriaga JB, Green A, James SL, et al. Dengue viruses cluster antigenically but not as discrete serotypes. Science. 2015;349 6254:1338-43; doi: 10.1126/science.aac5017. http://www.sciencemag.org/cgi/doi/10.1126/science.aac5017. 
9. Teixeira MG, João Bosco Siqueira J, Ferreira GLC, Bricks L, Joint G. Epidemiological Trends of Dengue Disease in Brazil (2000-2010): A Systematic Literature Search and Analysis. PLoS Neglected Tropical Diseases. 2013;7 12:e2520; doi: 10.1371/journal.pntd.0002520.

http://dx.plos.org/10.1371/journal.pntd.0002520.

10. Nunes ML, Oliveira SVd, Elkhoury MdR, Fonseca LX, Pereira SVC, Caldas EPd, et al. Evidência de circulação de hantavirus em área silenciosa da Região Amazônica. Revista Pan-Amazônica de Saúde. 2015;6 4:63-7; doi: 10.5123/S2176-62232015000400009. http://scielo.iec.pa.gov.br/scielo.php? script=sci_arttext\&pid=S2176-62232015000400009\&lng=en\&nrm=iso\&tlng=en.

11. Mota MTdO, Terzian AC, Silva MLCR, Estofolete C, Nogueira ML. Mosquito-transmitted viruses - the great Brazilian challenge. Brazilian journal of microbiology : [publication of the Brazilian Society for Microbiology]. 2016;47 Suppl 1:38-50; doi: 10.1016/j.bjm.2016.10.008.

http://eutils.ncbi.nlm.nih.gov/entrez/eutils/elink.fcgi?dbfrom=pubmed\&id=27818091\&retmode=ref\&cmd=prlinks.

12. Martins LC, Silva EVPd, Silva SPd, Cruz ACR, Pantoja JAdS, Medeiros DBdA, et al. First isolation of West Nile virus in Brazil. Memorias do Instituto Oswaldo Cruz. 2019;114 11:1; doi: 10.1590/0074-02760180332. http://www.scielo.br/scielo.php?script=sci_arttext\&pid=S007402762019000100305\&lng=en\&nrm=iso\&tlng=en.

13. Makino Y, Tadano M, Saito M, Maneekarn N, Sittisombut N, Sirisanthana V, et al. Studies on Serological Cross-Reaction in Sequential Flavivirus Infections. Microbiology and Immunology. 2013;38 12:951-5; doi: 10.1111/j.1348-0421.1994.tb02152.x. http://doi.wiley.com/10.1111/j.1348-0421.1994.tb02152.x.

14. Collins MH, McGowan E, Jadi R, Young E, Lopez CA, Baric RS, et al. Lack of Durable Cross-Neutralizing Antibodies Against Zika Virus from Dengue Virus Infection. Emerging Infectious Diseases. 2017;23 5:773-81; doi: 10.3201/eid2305.161630. http://wwwnc.cdc.gov/eid/article/23/5/16-1630_article.htm.

15. McCracken MK, Gromowski GD, Friberg HL, Lin X, Abbink P, De La Barrera R, et al. Impact of prior flavivirus immunity on Zika virus infection in rhesus macaques. PLoS Pathogens. 2017;13 8:e1006487. https://dx.plos.org/10.1371/journal.ppat.1006487.

16. Figueiredo LTM. The Brazilian flaviviruses. Microbes and Infection. 2000;2 13:1643-9; doi: 10.1016/S1286-4579(00)01320-4. http://linkinghub.elsevier.com/retrieve/pii/S1286457900013204.

17. Souza TML, Vieira YR, Delatorre E, Barbosa-Lima G, Luiz RLF, Vizzoni A, et al. Emergence of the East-Central-South-African genotype of Chikungunya virus in Brazil and the city of Rio de Janeiro may have occurred years before surveillance detection. Scientific Reports. 2019;9 1:2760; doi: 10.1038/s41598019-39406-9. https://www.nature.com/articles/s41598-019-39406-9.

18. Campos TDL, Durães-Carvalho R, Rezende AM, de Carvalho OV, Kohl A, Wallau GL, et al. Revisiting Key Entry Routes of Human Epidemic Arboviruses into the Mainland Americas through Large-Scale Phylogenomics. International Journal of Genomics. 2018;2018 3:1-9. https://www.hindawi.com/journals/ijg/2018/6941735/.

19. Tavares-Neto J, Freitas-Carvalho J, Nunes MRT, Rocha G, Rodrigues SG, Damasceno E, et al. [Serologic survey for yellow fever and other arboviruses among inhabitants of Rio Branco, Brazil, before and three months after receiving the yellow fever 17D vaccine]. Revista da Sociedade Brasileira de Medicina Tropical. 2004;37 1:1-6. https://www.ncbi.nlm.nih.gov/pubmed/?

term=Pesquisa+de+anticorpos+contra+arbov\%C3\%ADrus+e+o+v\%C3\%ADrus+vacinal+da+febre+amarela+em+uma+amostra+da+popula\%C3\%A7\%C3\%A

20. Nunes MRT, Barbosa TFS, Casseb LMN, Nunes Neto JP, Segura NdO, Monteiro HAdO, et al. [Arbovirus eco-epidemiology in the area affected by the CuiabáSantarém Highway (BR-163), Pará State, Brazil]. Cadernos de saude publica. 2009;25 12:2583-602. https://www.ncbi.nlm.nih.gov/pubmed/?term=Ecoepidemiologia+dos+arbov\%C3\%ADrus+na+\%C3\%A1rea+de+influ\%C3\%AAncia+da+rodovia+Cuiab\%C3\%A1-Santar\%C3\%A9m+ $(\mathrm{BR}+163) \% 2 \mathrm{C}+$ Estado+do+Par\%C3\%A1\%2C+Brasil.+Cadernos+de+Sa\%C3\%BAde+P\%C3\%BAblica\%2C+v.+25\%2C+n.+12\%2C+p.+2583\%E2\%80\%932602\%

21. Abad-Franch F, de Paula VS, Luz SLB, Grimmer GH, Braga WSM, Figueiredo LTM, et al. Mayaro Virus Infection in Amazonia: A Multimodel Inference Approach to Risk Factor Assessment. PLoS Neglected Tropical Diseases. 2012;6 10:e1846; doi: 10.1371/journal.pntd.0001846.

http://dx.plos.org/10.1371/journal.pntd.0001846.

22. Sakkas H, Bozidis P, Franks A, Papadopoulou C. Oropouche Fever: A Review. Viruses. 2018;10 4:175; doi: 10.3390/v10040175. http://www.mdpi.com/1999-4915/10/4/175.

23. CLARKE DH, Casals J. Techniques for hemagglutination and hemagglutination-inhibition with arthropod-borne viruses. American Journal of Tropical Medicine and Hygiene. 1958;7 5:561-73. https://www.ncbi.nlm.nih.gov/pubmed/13571577.

24. Shope RE. The use of a micro hemagglutination- inhibition test to follow antibody response after arthropod-borne virus infection in a community of forest animals. Anais de Microbiologia. 1963;11 Parte A:167-9. http://iah.iec.pa.gov.br/iah/fulltext/memo_iec/v7p175-178.pdf.

25. Vennes JW, Macdonald RE, Gerhardt P. Use of Logarithms to the Base 2 in recording Serological Reactions. Nature. 1957;180 4598:1363-; doi: 10.1038/1801363a0.

26. Rodriguez-Barraquer I, Marques ET, Cordeiro MT, Braga C, de Souza WV, Cummings DAT, et al. From Re-Emergence to Hyperendemicity: The Natural History of the Dengue Epidemic in Brazil. PLoS Neglected Tropical Diseases. 2011;5 1:e935; doi: 10.1371/journal.pntd.0000935.

http://www.pubmedcentral.nih.gov/articlerender.fcgi?artid=3014978\&tool=pmcentrez\&rendertype=abstract.

27. Castanha PMS, Cordeiro MT, MARTELLI CMT, Martelli CMT, SOUZA WV, MARQUES ETA, et al. Force of infection of dengue serotypes in a population-based study in the northeast of Brazil. Epidemiology and Infection. 2012;141 05:1080-8; doi: 10.1017/S0950268812001367.

http://www.ncbi.nlm.nih.gov/pubmed/22800513.

28. de Souza Bastos M, Itapirema E, Figueiredo LTM, Mourão MPG, de Figueiredo RMP, Gimaque JBL, et al. Simultaneous circulation of all four dengue serotypes in Manaus, State of Amazonas, Brazil in 2011. 2012;45 3:393-4. http://www.ncbi.nlm.nih.gov/pubmed/22760143.

29. Fritzell C, Rousset D, Adde A, Kazanji M, Van Kerkhove MD, Flamand C. Current challenges and implications for dengue, chikungunya and Zika seroprevalence studies worldwide: A scoping review. PLoS Neglected Tropical Diseases. 2018;12 7:e0006533; doi: 10.1371/journal.pntd.0006533. https://dx.plos.org/10.1371/journal.pntd.0006533. 
30. Nunes MRT, Faria NR, de Vasconcelos JM, Golding N, Kraemer MU, de Oliveira LF, et al. Emergence and potential for spread of Chikungunya virus in Brazil. BMC Medicine. 2015;13 1:102; doi: 10.1186/s12916-015-0348-x. https://bmcmedicine.biomedcentral.com/articles/10.1186/s12916-015-0348-x.

31. Ribeiro GS, Kikuti M, Tauro LB, Nascimento LCJ, Cardoso CW, Campos GS, et al. Does immunity after Zika virus infection cross-protect against dengue? The Lancet Global Health. 2018;6 2:e140-e1; doi: 10.1016/S2214-109X(17)30496-5. https://linkinghub.elsevier.com/retrieve/pii/S2214109X17304965.

32. Hladish TJ, Pearson CAB, Patricia Rojas D, Gomez-Dantes H, Halloran ME, Vazquez-Prokopec GM, et al. Forecasting the effectiveness of indoor residual spraying for reducing dengue burden. PLoS Neglected Tropical Diseases. 2018;12 6:e0006570; doi: 10.1371/journal.pntd.0006570.

http://dx.plos.org/10.1371/journal.pntd.0006570.

33. Dejnirattisai W, Jumnainsong A, Onsirisakul N, Fitton P, Vasanawathana S, Limpitikul W, et al. Cross-Reacting Antibodies Enhance Dengue Virus Infection in Humans. Science. 2010;328 5979:745-8; doi: 10.1126/science.1185181. http://www.ncbi.nlm.nih.gov/pubmed/20448183.

34. Halstead SB, Halstead SB. Controversies in dengue pathogenesis. Paediatrics and International Child Health. 2012;32 s1:5-9; doi: 10.1179/2046904712Z.00000000045. http://www.pubmedcentral.nih.gov/articlerender.fcgi?artid=3381449\&tool=pmcentrez\&rendertype=abstract.

35. Priyamvada L, Quicke KM, Hudson WH, Onlamoon N, Sewatanon J, Edupuganti S, et al. Human antibody responses after dengue virus infection are highly cross-reactive to Zika virus. Proceedings of the National Academy of Sciences of the United States of America. 2016;113 28:7852-7; doi: 10.1073/pnas.1607931113. http://www.pnas.org/content/113/28/7852.abstract.

36. Edeling MA, Rucker J, Austin SK, Shrestha B, Dowd KA, Mukherjee S, et al. Potent Dengue Virus Neutralization by a Therapeutic Antibody with Low Monovalent Affinity Requires Bivalent Engagement. PLoS Pathogens. 2014;10 4:e1004072; doi: 10.1371/journal.ppat.1004072. http://www.pubmedcentral.nih.gov/articlerender.fcgi?artid=3990716\&tool=pmcentrez\&rendertype=abstract.

37. Rothman AL. Immunity to dengue virus: a tale of original antigenic sin and tropical cytokine storms. Nature Reviews Immunology. 2011;11 8:532-43; doi: 10.1038/nri3014. http://www.nature.com/doifinder/10.1038/nri3014.

38. Wahala WMPB, Wahala WMPB, de Silva AM. The Human Antibody Response to Dengue Virus Infection. Viruses. 2011;3 12:2374-95; doi: 10.3390/v3122374. http://www.pubmedcentral.nih.gov/articlerender.fcgi?artid=3280510\&tool=pmcentrez\&rendertype=abstract.

39. Bardina SV, Bunduc P, Tripathi S, Duehr J, Frere JJ, Brown JA, et al. Enhancement of Zika virus pathogenesis by preexisting antiflavivirus immunity. Science. 2017;356 6334:175-80; doi: 10.1126/science.aal4365. http://eutils.ncbi.nlm.nih.gov/entrez/eutils/elink.fcgi? dbfrom=pubmed\&id=28360135\&retmode=ref\&cmd=prlinks.

40. Weiskopf D, Shresta S, Sidney J, de Silva AM, Weiskopf D, Sette A, et al. Comprehensive analysis of dengue virus-specific responses supports an HLAlinked protective role for CD8+ T cells. Proceedings of the National Academy of Sciences. 2013;110 22:E2046-E53; doi: 10.1073/pnas.1305227110. http://www.pubmedcentral.nih.gov/articlerender.fcgi?artid=3670335\&tool=pmcentrez\&rendertype=abstract.

41. De Góes Cavalcanti LP, Tauil PL, Alencar CH, Oliveira W, Teixeira MM, Heukelbach J. Zika virus infection, associated microcephaly, and low yellow fever vaccination coverage in Brazil: is there any causal link? The Journal of Infection in Developing Countries. 2016;10 06:563; doi: 10.3855/jidc.8575. https://jidc.org/index.php/journal/article/view/27367003.

42. Terzian ACB, Schanoski AS, Mota MTdO, da Silva RA, Estofolete CF, Colombo TE, et al. Viral Load and Cytokine Response Profile Does Not Support Antibody-Dependent Enhancement in Dengue-Primed Zika Virus-Infected Patients. Clinical Infectious Diseases. 2017;65 8:1260-5; doi: 10.1093/cid/cix558. http://eutils.ncbi.nlm.nih.gov/entrez/eutils/elink.fcgi?dbfrom=pubmed\&id=29017246\&retmode=ref \&cmd=prlinks.

43. Mourão MPG, Bastos MdS, de Figueiredo RP, Gimaque JBL, Dos Santos Galusso E, Kramer VM, et al. Mayaro Fever in the City of Manaus, Brazil, 20072008. Vector-Borne and Zoonotic Diseases. 2012;12 1:42-6; doi: 10.1089/vbz.2011.0669. http://www.liebertonline.com/doi/abs/10.1089/vbz.2011.0669.

44. Bastos MdS, Figueiredo LTM, Figueiredo LTM, Naveca FG, Monte RL, Lessa N, et al: Identification of Oropouche Orthobunyavirus in the Cerebrospinal Fluid of Three Patients in the Amazonas, Brazil. vol. 862012: 732-5.

45. Oliveira-ferreira J, Lacerda MVG, Brasil P, Ladislau JLB, Tauil PL, Daniel-ribeiro CT. Malaria in Brazil: an overview. Malaria Journal. 2010;9:115; doi: 10.1186/1475-2875-9-115. http://eutils.ncbi.nlm.nih.gov/entrez/eutils/elink.fcgi?dbfrom=pubmed\&id=20433744\&retmode=ref\&cmd=prlinks

46. Perez F, Llau A, Gutierrez G, Bezerra H, Coelho G, Ault S, et al. The decline of dengue in the Americas in 2017: discussion of multiple hypotheses. Tropical Medicine \& International Health. 2019;24 4:442-53; doi: 10.1111/tmi.13200. https://onlinelibrary.wiley.com/doi/abs/10.1111/tmi.13200.

47. Proenca-Modena JL, Milanez GP, Costa ML, Judice CC, Maranhão Costa FT. Zika virus: lessons learned in Brazil. - PubMed - NCBI. Microbes and Infection. 2018;20 11-12:661-9; doi: 10.1016/j.micinf.2018.02.008. https://linkinghub.elsevier.com/retrieve/pii/S1286457918300522.

48. Anders KL, Hay SI, Anders KL. Lessons from malaria control to help meet the rising challenge of dengue. The Lancet Infectious Diseases. 2012;12 12:97784; doi: 10.1016/S1473-3099(12)70246-3. http://www.pubmedcentral.nih.gov/articlerender.fcgi?artid=3574272\&tool=pmcentrez\&rendertype=abstract.

49. Laughlin CA, Fauci AS, Morens DM, Morens DM, Morens DM, Fauci AS, et al. Dengue Research Opportunities in the Americas. The Journal of Infectious Diseases. 2012;206 7:1121-7; doi: 10.1093/infdis/jis351. http://www.ncbi.nlm.nih.gov/pubmed/22782946.

50. WHO: El Niño may increase breeding grounds for mosquitoes spreading Zika virus. https://www.who.int/hac/crises/el-nino/22february2016/en/ (2016).

\section{Figures}




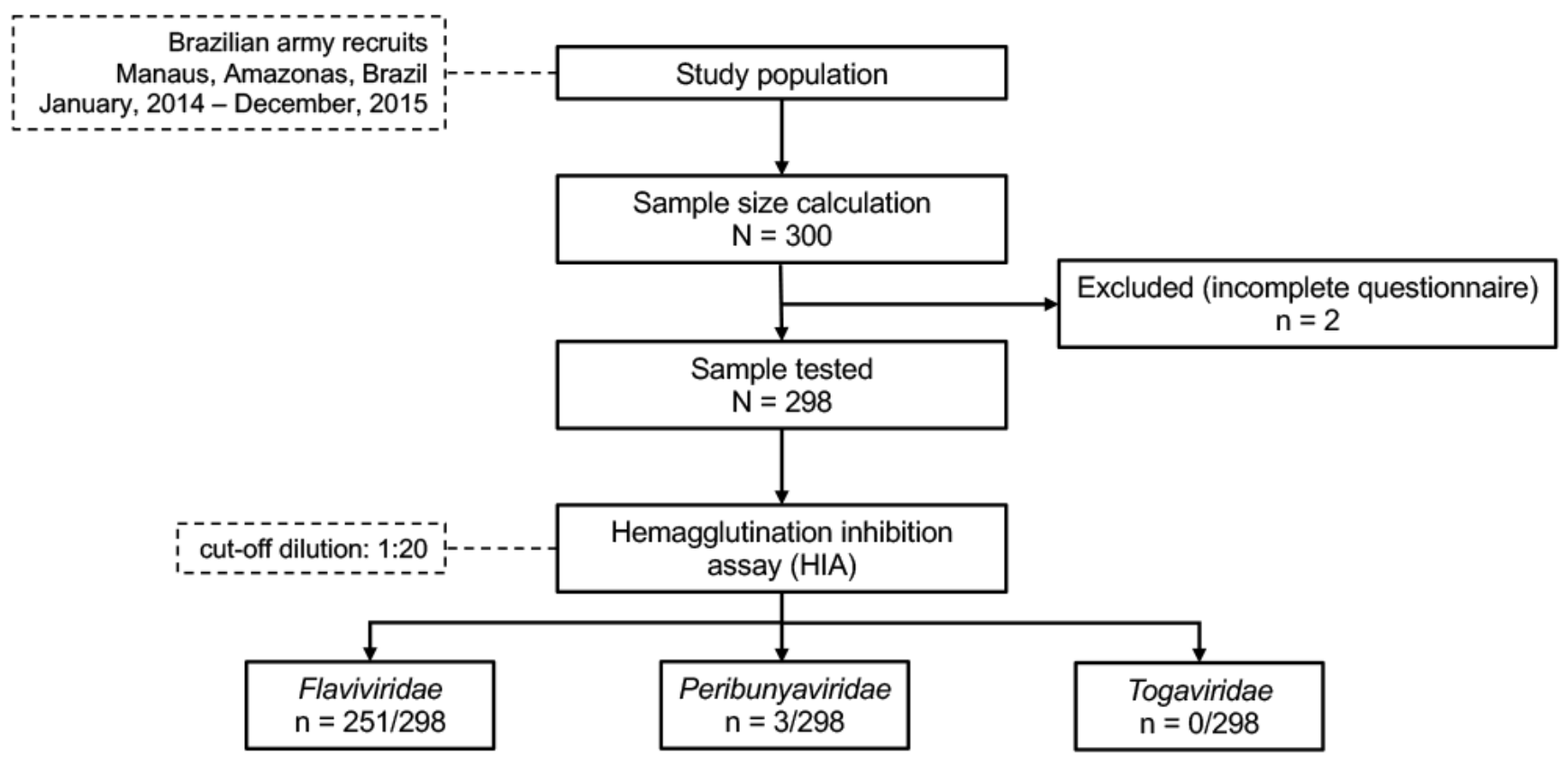

Figure 1

Sample collection flowchart (Strobes diagram)

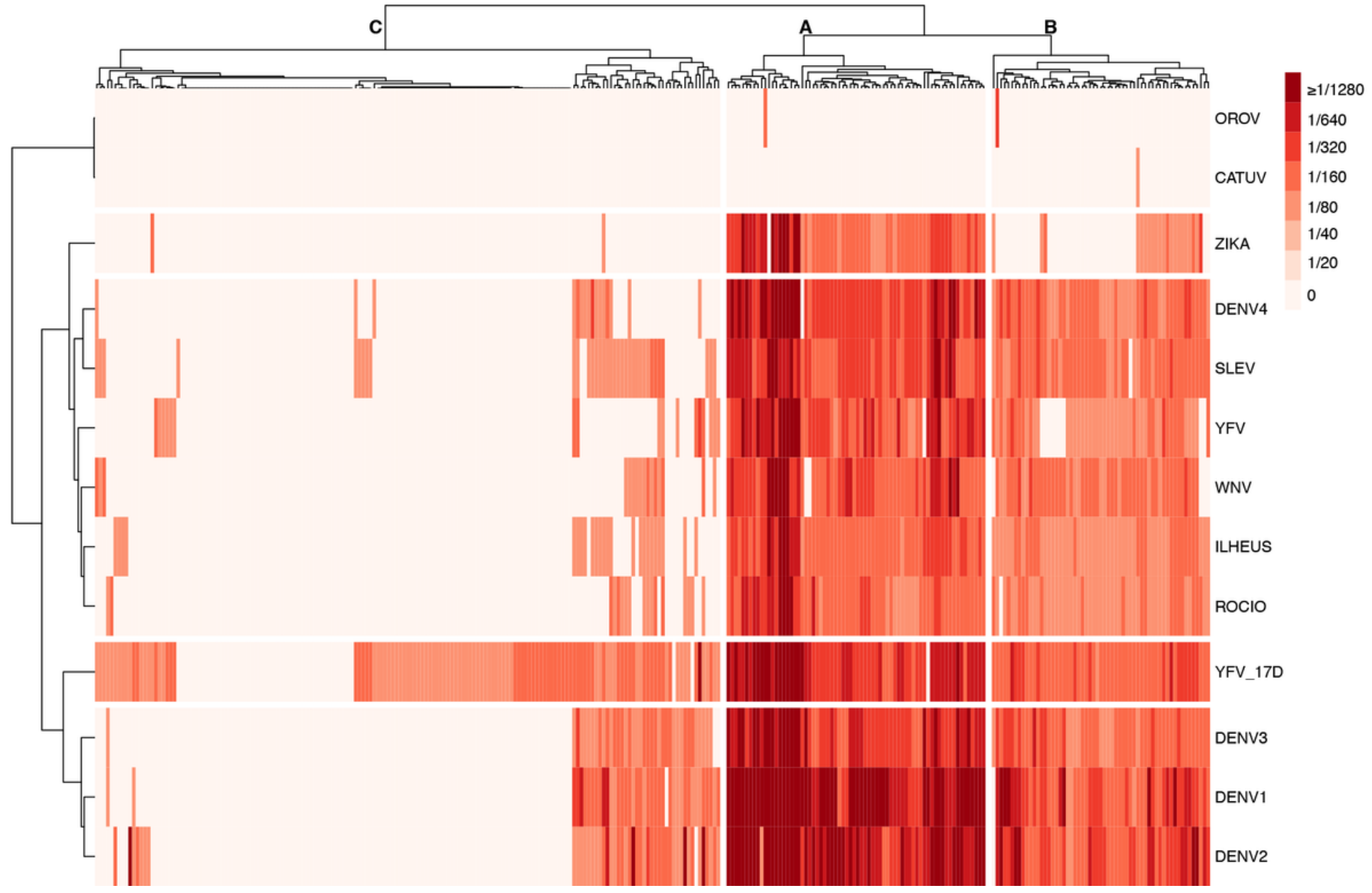


Figure 2

Seroreactivity against principal human Flaviviruses Patient samples $(n=298)$ were tested for antibodies against Flaviviruses by Hemagglutination inhibition assay (HIA). Heatmap represents the normalized antibody titres of individuals positive for at least one Flavivirus, clustered by titre. Groups: $A(n=70)$, $B$ ( $n=59)$, and $C(n=169)$

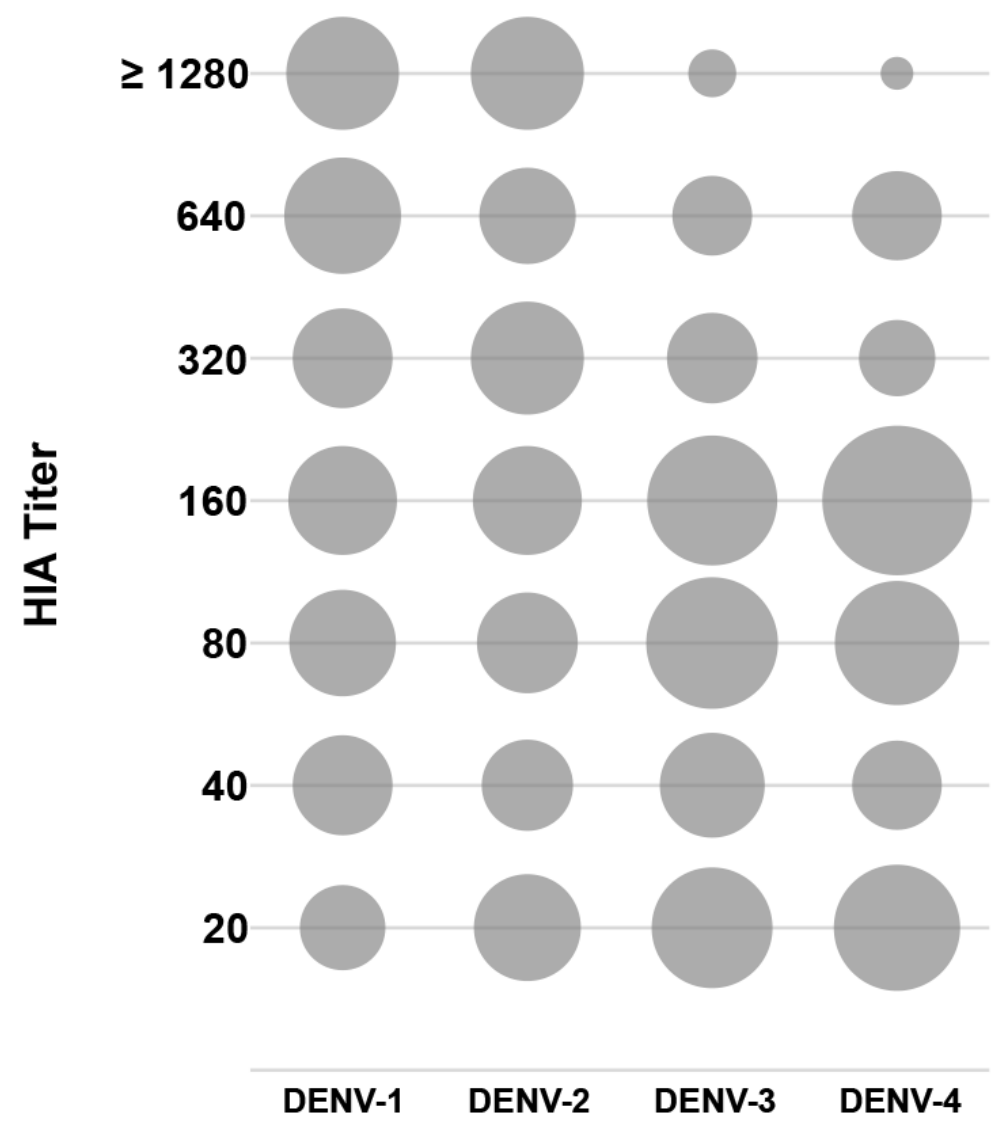

Figure 3

Distribution of Dengue virus antibody titres Dengue virus positive samples were plotted on a bubble chart as function of antibody titres and virus serotype. Bubbles show the column percentages for each virus and their sizes are proportional to their values. 
A

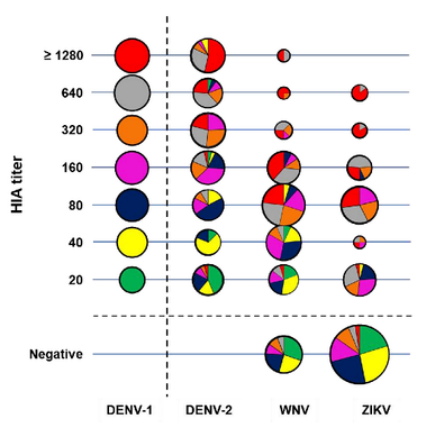

B

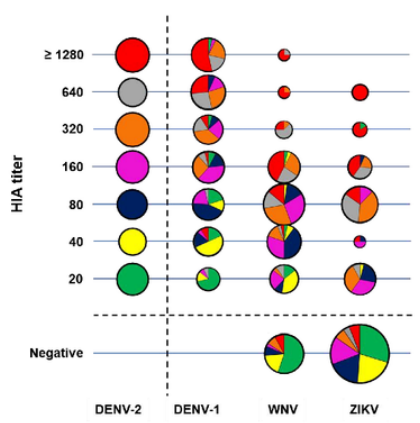

Figure 4

Antibody reactivity between Flaviviruses Dengue positive samples were used to evaluate cross-reactivity between emerging viruses. (A) DENV-1 or (B) DENV-2 HIA titres were compared with DENV-2 or -1, ZIKV or WNV antibody titres. Bubbles show the column percentages for each virus and their sizes are proportional to their values. All samples were considered positive with HIA titre $\geq 20$ units. Bubbles with pie chart represent distribution of individuals with reference to DENV-1 or DENV-2 HIA reactivity. 


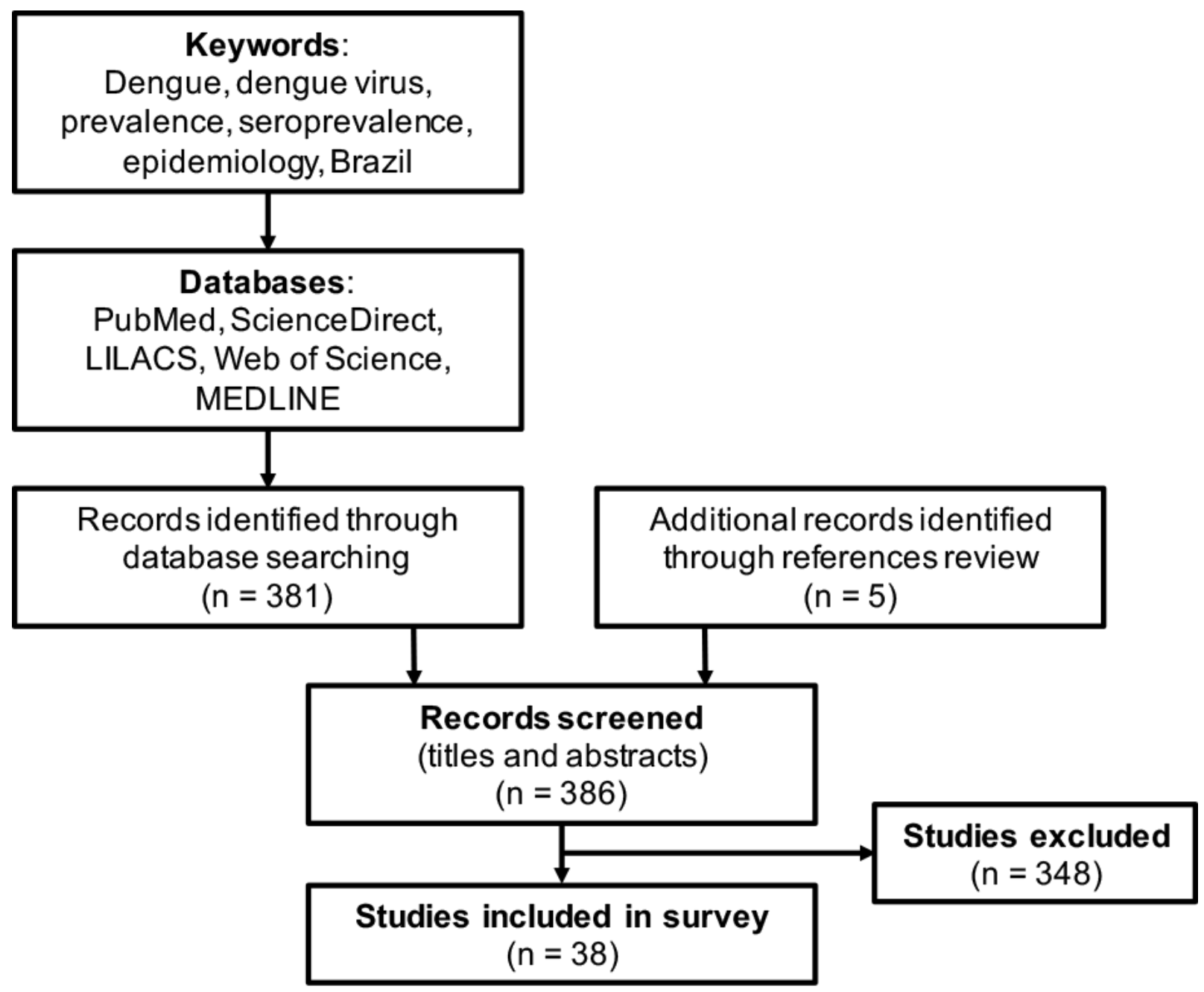

Figure 5

Preferred reporting items for systematic reviews and meta-analysis (PRISMA) flowchart for Dengue seroprevalence studies. 


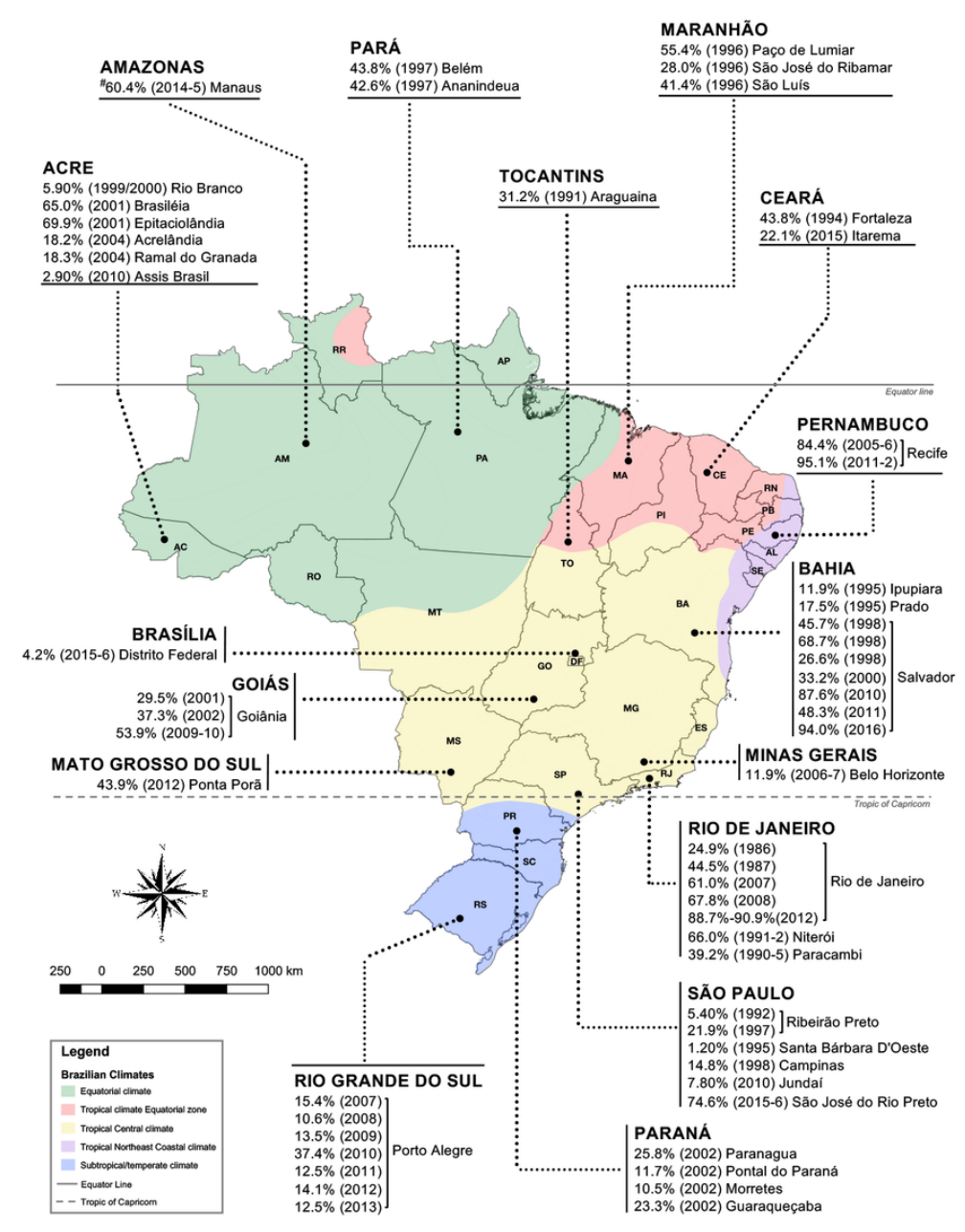

\section{Figure 6}

Summary of dengue prevalence studies reported between 1980 and 2020. QGIS software was used to plot tropical and subtropical areas along with study location, dengue seroprevalence and year of sample collection (Supplementary Table 1). All Brazilian states have confirmed DENV circulation but no seroprevalence data was available for some states (RO, RR, AP, PI, RN, PL, AL, SE, ES, DF and SC). *Manaus-AM 2015 data is from this study (refer Table 1). Note: The designations employed and the presentation of the material on this map do not imply the expression of any opinion whatsoever on the part of Research Square concerning the legal status of any country, territory, city or area or of its authorities, or concerning the delimitation of its frontiers or boundaries. This map has been provided by the authors.

\section{Supplementary Files}

This is a list of supplementary files associated with this preprint. Click to download.

- SupplementaryTableDengueprevalence.xIsx 